\title{
A tall order: Small area mapping and modelling of adult height among Swiss male conscripts
}

\author{
Radoslaw Panczak ${ }^{\mathrm{a}, \mathrm{b}}$, André Moser ${ }^{\mathrm{b}, \mathrm{c}}$, Leonhard Held ${ }^{\mathrm{d}}$, Philip A. Jones ${ }^{\mathrm{e}}$, Frank J. Rühli ${ }^{\mathrm{a}}$, Kaspar Staub ${ }^{\mathrm{a}, *}$ \\ a Institute of Evolutionary Medicine, University of Zurich, Winterthurerstrasse 190, CH-8057 Zurich, Switzerland \\ ${ }^{\mathrm{b}}$ Institute of Social and Preventive Medicine, University of Bern, Finkenhubelweg 11, CH-3012 Bern, Switzerland c Department of Geriatrics, \\ Inselspital, Bern University Hospital, University of Bern, CH-3012 Bern, Switzerland \\ ${ }^{d}$ Epidemiology, Biostatistics and Prevention Institute, University of Zurich, Hirschengraben 84, CH-8001 Zurich, Switzerland \\ e Department of Geography, Swansea University, Wallace Building, Singleton Park, Swansea SA2 8PP, UK
}

Corresponding author:

Kaspar Staub, Institute of Evolutionary Medicine, Winterthurerstrasse 190, CH-8057 Zurich, Switzerland. kaspar.staub@iem.uzh.ch (K. Staub).

Keywords: Stature, Switzerland, Spatial epidemiology, Spatial hierarchical Bayesian analysis, Integrated Nested Laplace approximation

\begin{abstract}
Adult height reflects an individual's socio-economic background and offers insights into the well-being of populations. Height is linked to various health outcomes such as morbidity and mortality and has consequences on the societal level. The aim of this study was to describe small-area variation of height and associated factors among young men in Switzerland.

Data from 175,916 conscripts (aged between 18.50 and 20.50 years) was collected between 2005 and 2011, which represented approximately $90 \%$ of the corresponding birth cohorts. These were analysed using Gaussian hierarchical models in a Bayesian framework to investigate the spatial pattern of mean height across postcodes. The models varied both in random effects and degree of adjustment (professional status, area-based socioeconomic position, and language region).

We found a strong spatial structure for mean height across postcodes. The range of height differences between mean postcode level estimates was $3.40 \mathrm{~cm}$ according to the best fitting model, with the shorter conscripts coming from the Italian and French speaking parts of Switzerland. There were positive socioeconomic gradients in height at both individual and area-based levels. Spatial patterns for height persisted after adjustment for individual factors, but not when language region was included. Socio- economic position and cultural/natural boundaries such as language borders and mountain passes are shaping patterns of height for Swiss conscripts. Small area mapping of height contributes to the understanding of its cofactors.
\end{abstract}




\section{Introduction}

The average height of a given adult population serves as a measure of nutritional status and living conditions across the first 20 years of life, capturing the influence of periods of deprivation and subsequent catch-up growth (Bogin, 1999). Whereas genes are largely responsible for an individual's height potential (c80\%), variation in average height over time and across sub-populations can be driven by systematic differences in diet, disease environment, economic conditions, workload and healthcare, which in turn determine the extent to which individuals in these subpopulations realize their genetic potential (Grasgruber et al., 2016; McEvoy and Visscher, 2009; Steckel, 2009). Thus, adult height reflects an individual's socio-economic background and offers insights into the well-being of populations (A'Hearn et al., 2009; Akachi and Canning, 2015; Baten and Blum, 2014; Dalou, 2015; Komlos, 2008).

Height can also be linked to various health outcomes such as morbidity and mortality (Engeland et al., 2003). Overall, being taller seems to be negatively related to all-cause and cardiovascular disease (CVD) mortality, but positively related with cancer mortality (The Emerging Risk Factors Collaboration, 2012). However, the precise mechanisms underlying these associations have yet to be identified. Furthermore, height has consequences on a societal level: taller men evaluate their life as more favourable (Deaton and Arora, 2009), have greater success in the marriage market, and have greater career chances in the labour market compared to shorter men (Herpin, 2005; Magnusson et al., 2006). Similar to what is found in Germany, a height premium was also associated with 5 per mille additional salary per cm of stature (or 1.52 per mille per inch) in Switzerland in 2002 (Gautschi and Hangartner, 2006; Heineck, 2005; Hübler, 2009). The positive effect of height on labour market outcomes has been described for various countries (Case and Paxson, 2008; Gao and Smyth, 2010; Persico et al., 2004; Schultz, 2002; Vogl, 2014), and studies using twin data imply that in the case of men, cognitive ability could explain the effect of height on earnings (Böckerman and Vainiomäki, 2013).

Adult height varies geographically between world regions (Deaton, 2007; Natale and Rajagopalan, 2014) and even between Northern and Southern Europe (McEvoy and Visscher, 2009). However, less is known about small-area differences within countries and to the best of our knowledge, there are only very few studies that have evaluated national height differences on the small-area level (Ayuda and Puche-Gil, 2014; Baten, 2009). Small-area analyses are able to describe clusters and geographic variations of a given outcome (Elliott and Wartenberg, 2004). In the case of height, this might be of particular interest because people with high socioeconomic position usually tend to live near others with high socioeconomic position, irrespective of administrative units such as districts or cantons (Panczak et al., 2016). Such spatially organized socioeconomic and/or demographic effects often continue to be observed after controlling for individual-level factors (Panczak et al., 2012).

Because average height continues to differ between socio- economic groups in modern Western societies (Hiermeyer, 2009; Huang et al., 2015; Rühli et al., 2008), such small-area studies could further point to genetic and socioeconomic associations with height. Switzerland serves as an ideal basis for such studies because of its cultural and demographic diversity and historical stability (four official language regions, and significant variation of geographical and socioeconomic environment). Studies of mortality and obesity have already shown the benefits of small-area analyses in Switzerland (Moser et al., 2014; Panczak et al., 2016, 2012). Moreover, military conscription provides a large, spatially referenced dataset of the anthropometric status of young men at a prescribed age. The data are collected yearly and, amongst other things, include standardized height measurements (Staub et al., 2013b).

Adult height in Switzerland and its historical development have been described in depth elsewhere (Staub et al., 2013a), but it is important to note that the positive height trend of Swiss conscripts has plateaued since the 1990s (1970s birth years) on a level of 178.2-178.3 cm for men (Staub et al., 2014, 2011). Previous studies documented large scale geographical differences in average height in modern Switzerland and found significant differences between Grossregionen based on Swiss Household Panel data (Kues, 2010) and between cantons or districts based on conscription data (Hermanussen et al., 2014; Rühli et al., 2008; Staub et al., 2013a).

The main goal of this study was to extend this research and explore spatial patterns of height with a higher spatial resolution. We hypothesised that there is a spatial pattern in height among young Swiss men and that this variation is partly explained by socioeconomic and cultural factors. In this paper we use spatial statistical methodology (Section 2), to gain area-based estimates of heights from differently specified models (Section 3) before discussing these results in the light of the current state of knowledge (Section 4) and reaching a conclusion (Section 5).

\section{Materials and methods}




\subsection{Data sources}

The recruitment process of the Swiss Armed Forces has been described in details elsewhere (Bruggisser et al., 2016; Panczak et al., 2016, 2014), in brief, all men are reviewed for recruitment during the year in which they turn 19. The military assessments include, among others, a standardized measurement of height (rounded to integers) of every conscript (without shoes and in light underwear), including those who get deferred or exempted (Bundesgesetz über die Armee und die Militärverwaltung, Militärge- setz MG, 510.10, Art. 2; MG Art. 9, Verordnung über die Rekrutierung VREK, 511.11, Art. 3 and Art. 9) (Panczak et al., 2016, 2014). Swiss Armed Forces provided a complete set of anonymized conscript records from 1.1.2005 to 31.12.2011 which included date of birth, date of conscription, height, current occupation, postcode of place of residence (further referred to as 'postcode') and stage of conscription (first, regular visit versus reassessment). Information on the place of birth was not available. We obtained a dataset of postcode boundaries from the Federal Directorate of Cadastral Surveying ("Release 7-1. Mai 2013", boundaries as per 31st of March 2013) (Panczak et al., 2016, 2014).

\subsection{Data availability and ethics statement}

The data are available from the Swiss Armed Forces (Logistikbasis der Armee LBA San, 2014) upon submission and approval of a study protocol. According to Swiss federal law (Bundesgesetz über die militärischen Informationssysteme MIG, BG 510.91, Art. 2, 9, 24-29), the Swiss Armed Forces are authorized to make the data accessible in anonymous form for academic research. The Swiss Armed Forces fully anonymized the records by removing all names, socialsecurity numbers, and exact residential addresses. Because Swiss conscription is mandatory and the anthropometric measurements used in this study are nonclinical, governmental data, informed consent was not required. When the analyses are based on anonymized, nonclinical governmental data additional ethical approval is not needed (Swiss data privacy act, SR 235.1; 19.6.1992 and Federal Act on Research involving Human Beings HRA, 810.30; 1.1.2014) (Bruggisser et al., 2016; Panczak et al., 2016, 2014).

\subsection{Study population}

We included all male conscripts appearing for the first, regular assessment, aged between 18.50 and 20.50 years. We excluded women, conscripts appearing for reassessment, conscripts below 18.5 and above 20.5 years old (who requested to undergo conscription either before or after the year in which they turned 19), those with missing or implausible postcode, those with height beyond a plausible range (below $130 \mathrm{~cm}$ or above $220 \mathrm{~cm}$ ) and conscripts with missing or insufficient data on occupation (Panczak et al., 2014). The spatial resolution for the study was obtained by using place of residence at the time of conscription, and standardizing the postcodes from various years to that on 31.3.2013 to align them across datasets (Swiss Federal Statistical Office, 2014a).

\subsection{Representativeness}

Currently, no dataset exists that allows precise assessment of the representativeness of the conscript population compared to the total population of young men in Switzerland. However, an earlier study using similar sources (Panczak et al., 2014) estimated data to be of high coverage (>90\%). Swiss Armed Forces declare that the medical causes of up to $10 \%$ of young men who were judged unfit for service in absentia, included the full range of severe diseases and severe physical and psychiatric disabilities (Bruggisser et al., 2016), were not necessarily linked to growth or height.

\subsection{Variables}

Height was the main outcome. We captured individual level SEP by the occupation, which we treated similarly to previous studies based on this data (Panczak et al., 2016, 2014), by converting the occupation at the time of measurement to the International Standard Classification of Occupations (ISCO-08) code according to the International Labour Organization standards (International Labour Organization, 2014). The ISCO major groups were then aggregated to three major, hierarchical categories of professional status (Hallström et al., 2011): 'Low' (ISCO major groups 7-9), 'Medium' (ISCO major groups 3-6) and 'High' (ISCO major groups 1 and 2, and students) along with creating a separate category for individuals who were still in education ('Pupils'). Postcodes were classified into three language regions ('German', French; and 'Italian') according to where they were located in relation to the Swiss Federal Statistical Office classification of communities. Finally, we calculated the median value of the Swiss neighbourhood index of socioeconomic position (Swiss-SEP; (Panczak et al., 2012)) for each of the postcodes (Supplementary Fig. 1) and divided it into quintiles. 


\subsection{Statistical analyses}

We reported absolute and relative frequencies of the study population and the mean and standard deviation (SD) of height across covariates. We applied hierarchical Gaussian models in a Bayesian framework with individual level data to investigate the spatial pattern of height across postcodes, taking in account potential confounders (Blangiardo et al., 2013; Gómez-Rubio and López-Quílez, 2010; Schrödle and Held, 2010). This strategy allowed us to model spatial dependency between regions and to obtain smoothed estimates of height across postcodes, particularly for regions with a small number of conscripts (Earnest et al., 2007). Bayesian approaches in hierarchical modelling have the advantage of 'borrowing' information from other postcodes, i.e., by the implications of exchangeability, an estimate for a specific postcode is made using information from its neighbouring regions, leading to a shrinkage towards the mean and narrower uncertainty estimates. Such modelling can be done in a more flexible way than frequentist approaches (Spiegelhalter et al., 2004). As a result, this approach did not force us to rely on the unlikely assumption that height is independent across spatial units (Feltbower and Manda, 2012).

Our hypothesis was that height varies across the country and this variation is associated with socioeconomic and cultural factors. To test this we compared models that varied in the degree of adjustment and the type of random effects used. We fitted ordinary models, models using spatially unstructured effects and, finally, spatially unstructured and spatially structured effects combined (BYM model introduced by Besag et al. (1991)). In addition, we also varied the degree of adjustment by including occupational status and Swiss-SEP in the first step, and language region in the second.

Similar to previous studies (Assareh et al., 2014; Bernardinelli et al., 1995; Blangiardo et al., 2013; Carroll et al., 2015; Rue et al., 2009), unstructured and structured random effects were modelled as independent zero-mean Gaussian random variables with vague Gamma $(1,0.01)$ and Gamma $(1,0.001)$ priors on the precision parameter. For the fixed effects, we used the zero-mean Gaussian priors with a variance of 103 and the default Gamma $(1,0.00005)$ prior was used for the residual variance. Due to the sample size, prior sensitivity was not considered an issue. The deviance information criterion (DIC) was used to compare model fits (Spiegelhalter et al., 2002).

Postcodes with contiguous borders were designated as neighbours. Postcodes with no observations were represented with one dummy observation with missing outcome and were assigned to the reference (most frequent) categories of the analyzed covariates. All analyses were done in R 3.2.3 (The R Core Team, 2014) using the R-INLA package [(Rue et al., 2009), www.r-inla.org]. INLA implements the Integrated Nested Laplace approximation approach for latent Gaussian models (Rue et al., 2009). We used choropleth maps (Harrower and Brewer, 2003) to present both postcodelevel estimates of height and their corresponding posterior probabilities classified according to Richardson et al. (2004).

\section{Results}

The initial sample consisted of 265,928 conscripts of which we excluded 1571 (0.6\%) women, 10,305 (3.9\%) conscripts appearing for reassessment, $7(<0.1 \%)$ with a missing date of birth, $30(<0.1 \%)$ with implausible heights, $3(<0.1 \%)$ with missing postcodes, 15,311 (5.8\%) below 18.5 and 50,328 (18.9\%) above 20.5 years old and 12,457 (4.7\%) with missing or imprecise occupations. Therefore the final sample consisted of 175,916 conscripts. On 31.3.2013, there were 3187 postcodes in Switzerland. The mean number of conscripts in each postcode was 55.19 (standard deviation (SD): 82.72) and ranged from zero (in 46 (1.4\%) postcodes) to 962 (in one postcode).

The overall average height of the conscripts $(N=175,916)$ between 2005 and 2011 was $178.19 \mathrm{~cm}(95 \% \mathrm{Cl} 178.15-$ $178.23, \mathrm{SD}=6.48 \mathrm{~cm}$, median $=178 \mathrm{~cm}$ ) and was nearly symmetrically distributed (skewness $=0.07$ ). Height varied across the socio- demographic characteristics of the conscripts and the areas they lived in. Table 1 shows the average height across analysed covariates. There was a clear gradient of increasing average height across the strata of professional status with the shortest conscripts being in the 'Low' group $(177.83 \mathrm{~cm})$ as opposed to the tallest conscripts being in the 'High' $(178.59 \mathrm{~cm})$ and 'Pupil' $(178.63 \mathrm{~cm})$ groups. Conscripts were also shorter in the French and, particularly, in the Italian speaking areas of Switzerland. An increasing gradient also existed between the 5th (lowest SEP, $177.74 \mathrm{~cm}$ ) and 1st (highest SEP, $178.84 \mathrm{~cm}$ ) quintiles of neighbourhood SEP index. Table 2 shows the comparison of the model fit according to the different types of random effects and adjustment used in the analysis. Three BYM models (Models 6-7) provided a better fit than similarly specified models without random effects (Models 1 and 2) or with unstructured spatial effects only (Models 3, 4 and 5). Adjusting for professional status and Swiss-SEP further improved the fit of the BYM model (Model 7 compared to 6). The addition of the language region variable 
(Model 8), however, slightly increased the value of the DIC indicating a worse fit. Using the DIC results we selected BYM models (6, 7 and 8).

Fig. 1 (top map) shows the estimates of postcode level height difference, and Fig. 2 (top map) - corresponding posterior probabilities, from the unadjusted BYM model 6. There was heterogeneity of height between the postcodes. The range of height differences from the national mean between postcode level estimates was $3.51 \mathrm{~cm}$ (range 1.65 $\mathrm{cm}$ to $+1.86 \mathrm{~cm}, \mathrm{SD}=0.52$ ). Some large-scale spatial patterns emerged from the map with concentrations of postcodes with taller conscripts scattered across the German speaking part of Switzerland, particularly in the eastern part of canton Valais, and in a belt of northern areas stretching between cantons Basel, Aargau, Zurich, Schaffhausen and south towards cantons of Zug and Schwyz. Pockets of higher estimates were also found around the city of Bern and in Graubünden.

In contrast, postcodes with shorter conscripts were concentrated in the Italian-speaking canton of Ticino and the Western French speaking part of Switzerland (including the French speaking part of canton of Valais), the small Italian speaking part of canton of Grisons (Val Poschiavo), as well as in parts of North Eastern cantons (St. Gallen, Appenzell Ausserrhoden, Appenzell Innerrhoden).

Fig. 1 (middle map) shows postcode level estimates of height among conscripts from adjusted model 7. The range of height differences from the national mean was similar to model 1 (ranging by $3.40 \mathrm{~cm}$ from $1.69 \mathrm{~cm}$ to $+1.71 \mathrm{~cm}, \mathrm{SD}=$ 0.51). The spatial patterns were also largely similar as was variance of random effects (Table 3 ). Some areas where shorter conscripts were concentrated in the unadjusted model were lost in the adjusted model 7. This was found in the canton of Bern, Central Switzerland and the Western part of Valais whereas the regions around the lake of Geneva and the city of Basel did not show small clusters of taller conscripts any longer.

Fig. 1 (bottom map) shows the estimates of height from model 8 (adjusted for language region). A large part of the spatial patterning of height revealed by the two previous two models was captured by the language region covariate and disappeared from the map (e.g., areas of low height in Ticino). This was also clearly indicated in the reduction of variance of random effects (Table 3). The range of height differences from the national mean between postcode level estimates decreased to $1.28 \mathrm{~cm}$ (range $0.54 \mathrm{~cm}$ to $+0.74 \mathrm{~cm}, \mathrm{SD}=0.15$ ). Some concentrations of postcodes with height difference persisted, but were smaller and weaker in effect. Higher values were only scattered in the German speaking part of Valais and parts of Graubuenden and Schwyz, and lower values in the North Eastern part of Switzerland, parts of Jura and around the city of Geneva.

Table 3 shows the association of the covariates (fixed effects) from models $6-8$. There were significant positive effects of both the individual and the area based SEP indicators. For instance, in fully adjusted Model 8 , the height difference comparing 'High' to 'Medium' professional status was $0.65 \mathrm{~cm}(95 \%$ credible interval (Cl) $0.56-0.74)$ and with SwissSEP index (reported as per 10 units increase; the original Swiss-SEP ranges from 0 to 100$)$ it was $0.28 \mathrm{~cm}(95 \% \mathrm{Cl} 0.23-$ 0.34). There was a strong negative effect of the language region, with an adjusted height difference of $0.66 \mathrm{~cm} 95 \% \mathrm{Cl}$ 0.83 to 0.49$)$ for French speaking and $1.54 \mathrm{~cm}(95 \% \mathrm{Cl} 1.88$ to 1.20) for Italian speaking regions. The estimates across covariates obtained in models 1-7 were very similar (Supplementary Tables 1 and 2).

Of note, the effect of area-based SEP decreased when spatially structured effects were considered (Model 7 vs. Model 4 ) or when language region was considered (Model 5 vs. 4), potentially indicating 'confounding due to location' phenomena (Clayton et al., 1993; Hodges and Reich, 2010) and implying differing SEP index across language regions: The mean SEP index for the German speaking postcodes was 6.16 (SD = 2.91) and thus higher than in the French (5.94, $\mathrm{SD}=3.05)$ and Italian speaking $(5.84, \mathrm{SD}=4.19)$ postcodes.

\section{Discussion}

The aim of this study was to describe small-area variation and socioeconomic associations of height among young men in Switzerland using recent waves of conscription data. Using records from 2005 to 2011, we found a strong spatial structure of height across postcodes. Clear and constant concentrations of high and low values emerged, but regional outliers were also present. Observed patterns resembled the language divisions of Switzerland, with shorter conscripts in the Italian and French speaking parts of Switzerland. Lastly, the results identified socioeconomic gradients in height both on individual and area- based levels.

Our study is the first to reveal small-area differences in height on the postcode level. The main strengths of this study are its use of large, representative and objectively measured data and the size of the sample, which allowed for a 
high-resolution spatial analysis. Furthermore, the study also benefits from the application of methods that handle small area analyses in such large samples, which has only become possible in the last two decades. As with earlier studies using similar data (Panczak et al., 2016, 2014), this study also has important limitations. First, the results are applicable to young men with Swiss citizenship only and cannot be transferred to women, other age groups or to persons without Swiss citizenship. Second, the language region had to be included as an ecological variable because information about the mother tongue was not available on the individual level. Third, occupation is a limited measure of socioeconomic position, particularly for young individuals (Fuchs, 2004; Staub et al., 2010), in particular, there are no details available on the educational level in general, and in particular of those young men registered as "pupils". As a significant number of conscripts were still in school and it will take time for them to establish themselves in the labour market, we attempted to mitigate these limitations by additionally using an area-based SEP index, which at the moment is the only such indicator available in Switzerland (Panczak et al., 2012). Fourth, conscription data do not provide information about the migration background of the young men. Estimates made by the Swiss Federal Office of Statistics in 2014 show that up to 15\% of males aged 18-22-years with Swiss citizenship have a 2nd or 3rd generation migration background (Swiss Federal Statistical Office, 2014b). Fifth, our data do not include the place of birth of the conscripts, which might be of particular importance when focussing on early life environments and their association with adult height.

Our results confirm findings from earlier studies on the levels of cantons or Grossregionen (Kues, 2010; Rühli et al., 2008; Staub et al., 2013a) that young Swiss men are shorter in Ticino (similar to the 19th century) and in East Switzerland (the cantons Appenzell Ausserrhoden and Appenzell Innerrhoden, in particular). The national Swiss average $(178.19 \mathrm{~cm})$ fits well with estimates from Central Europe (Hatton and Bray, 2010). Average height in Northern Switzerland matches well with the levels observed in South-East Germany $(178.0 \mathrm{~cm}$ in 2000/2001, (Hiermeyer, 2009)), whereas conscripts in Ticino are similar to the Northern Italians (176.48 cm in the North East for the $1980 \mathrm{~s}$ birth years (Arcaleni, 2006)). The significant effect of individual SEP (as measured by occupational status) on the height of the Swiss conscripts has been observed previously (Rühli et al., 2008). Previous studies suggest that SEP might influence height through a complex interplay between several factors such as parental education and assortative mating between both parents on the one hand and nutrition, disease environment, or physical workload during the growing years on the other hand (Bogin, 1999; Galobardes et al., 2006; Steckel, 2009; Stulp and Barrett, 2016).

The spatial patterns might result from several factors. On the one hand, the significant individual and area-based socio- economic effects suggest that the spatial pattern of height, particularly in the midlands of Switzerland, might partially follow the distribution of socio-economic groups across the country (who lives where at the time of measurement?) (Panczak et al., 2012) (Supplementary Fig. 2, top map). On the other hand, the average height also follows natural/cultural boundaries, such as language borders and mountain passes, indicating also a possible influence of genes and/or culture particularly in the alpine areas in Southern Switzerland (Supplementary Fig. 2, bottom map). Studies have shown that genetic data of the population structure around and within Switzerland varies by language and the corresponding language areas (Novembre et al., 2008). Moreover, the language borders, partially accentuated by high mountain passes, for example between Valais and Ticino, serve as a historically stable proxy for diverse cultures and are an obstacle for population exchange (Mayer, 1951). There is some evidence that the reduced intermixing and interaction between these communities could contribute to differences in growth and adult height (Aßmann and Hermanussen, 2013; Hermanussen et al., 2014). Regional nutritional patterns, especially for animal protein and milk consumption, proved to be an important determinant of regional variance in adult height (Baten, 2009). Unfortunately, we could not test this hypothesis because nation-wide and reliable small-area information on nutritional patterns do not yet exist for Switzerland. Moreover, there might exist more factors influencing the observed patterns, which have yet to be identified.

\section{Conclusion}

Our results indicate discrepancies in adult height among Swiss conscripts. Small area mapping of height contributes to the understanding of this biological phenotypic feature by adding to the debate that both individual/area-based socioeconomic position and cultural/natural boundaries such as language borders and mountain passes are important factors. Height adds to the list of traits like obesity or life expectancy, which show a strong spatial variation, irrespective of administrative boundaries. In particular, the coaction of both cofactors, language regions (also reflecting genetic background) and individual/area-based socio-economic background offer potential for further studies focussing on the underlying mechanisms. Researchers and policy makers should consider including such 
dimensions when planning studies and/or interventions. However, further studies modelling small area differences in height are needed to better distinguish between all the contributing factors. For example, focussing on the Southern cantons Valais and Ticino and particularly on the language boarder areas (maybe even based on individual residential addresses) from conscription and other data sources (including women, other age groups, or longitudinal growth data), adding individual/ecological variables for nutrition, or analysing height clusters within larger cities might further enhance the state of knowledge.

\section{References}

Aßmann, C., Hermanussen, M., 2013. Modeling determinants of growth: evidence for a community-based target in height? Pediatr. Res. $74,88-95$. doi:http://dx. doi.org/10.1038/pr.2013.50.

A'Hearn, B., Peracchi, F., Vecchi, G., 2009. Height and the normal distribution: evidence from Italian military data. Demography 46, 1-25.

Akachi, Y., Canning, D., 2015. Inferring the economic standard of living and health from cohort height: evidence from modern populations in developing countries. Econ. Hum. Biol. 19, 114-128. doi:http://dx.doi.org/10.1016/j. ehb.2015.08.005.

Arcaleni, E., 2006. Secular trend and regional differences in the stature of Italians, 1854-1980. Econ. Hum. Biol. 4, $24-38$. doi:http://dx.doi.org/10.1016/j. ehb.2005.06.003 S1570-677X(05)00036-5 [pii].

Assareh, H., Ou, L., Chen, J., Hillman, K., Flabouris, A., Hollis, S.J., 2014. Geographic variation of failure-to-rescue in public acute hospitals in New South Wales, Australia. PLoS One 9, e109807. doi:http://dx.doi.org/10.1371/journal. pone.0109807.

Ayuda, M.I., Puche-Gil, J., 2014. Determinants of height and biological inequality in Mediterranean Spain, 1859-1967. Econ. Hum. Biol. 15, 101-119. doi:http://dx. doi.org/10.1016/j.ehb.2014.07.003.

Böckerman, P., Vainiomäki, J., 2013. Stature and life-time labor market outcomes: accounting for unobserved differences. Labour Econ. 24 , 86-96. doi:http://dx. doi.org/10.1016/j.labeco.2013.06.003.

Baten, J., Blum, M., 2014. Why are you tall while others are short? Agricultural production and other proximate determinants of global heights. Eur. Rev. Econ. Hist. 18, 144-165. doi:http://dx.doi.org/10.1093/ereh/heu003.

Baten, J., 2009. Protein supply and nutritional status in nineteenth century Bavaria, Prussia and France. Econ. Hum. Biol. 7, 165-180.

doi:http://dx.doi.org/10.1016/j. ehb.2009.02.001.

Bernardinelli, L., Clayton, D., Montomoli, C., 1995. Bayesian estimates of disease maps: how important are priors? Stat. Med. 14, $2411-2431$. doi:http://dx.doi. org/10.1002/sim.4780142111.

Besag, J., York, J., Mollié, A., 1991. Bayesian image restoration, with two applications in spatial statistics. Ann. Inst. Stat. Math. 43, 1-20. doi:http://dx.doi.org/ 10.1007/BF00116466.

Blangiardo, M., Cameletti, M., Baio, G., Rue, H., 2013. Spatial and spatio-temporal models with R-INLA. Spat. Spatiotemporal Epidemiol. 7, 39-55. doi:http://dx. doi.org/10.1016/j.sste.2013.07.003.

Bogin, B., 1999. Patterns of Human Growth, 2nd ed. Cambridge University Press, Cambridge.

Bruggisser, M., Burki, D., Häusler, M., Rühli, F.J., Staub, K., 2016. Multivariable analysis of total cholesterol levels in male Swiss Armed Forces conscripts 2006- 2012 ( $\mathrm{N}=174,872$ ). BMC Cardiovasc. Disord. 16, 1-13.

Carroll, R., Lawson, A.B., Faes, C., Kirby, R.S., Aregay, M., Watjou, K., 2015. Comparing INLA and OpenBUGS for hierarchical Poisson modeling in disease mapping. Spat. Spatiotemporal Epidemiol. 14-15, 45-54. doi:http://dx.doi.org/10.1016/j. sste.2015.08.001.

Case, A., Paxson, C., 2008. Stature and status: height, ability, and labor market outcomes. J. Polit. Econ. 116, 499-532. doi:http://dx.doi.org/10.1086/589524.

Clayton, D.G., Bernardinelli, L., Montomoli, C., 1993. Spatial correlation in ecological analysis. Int. J. Epidemiol. 22, $1193-12028144305$.

Dalou, A.Y.A., 2015. Height of Northern Jordanian middle-class adults, born 1960-1990 in the response to improving socio-economic conditions. Econ. Hum. Biol. 22, 155-160. doi:http://dx.doi.org/10.1016/j.ehb.2015.12.001.

Deaton, A., Arora, R., 2009. Life at the top: the benefits of height. Econ. Hum. Biol. 7, 133-136. doi:http://dx.doi.org/10.1016/j.ehb.2009.06.001 S1570-677X(09)00046-X [pii].

Deaton, A., 2007. Height, health, and development. Proc. Natl. Acad. Sci. U. S. A. 104, 13232-13237.

doi:http://dx.doi.org/10.1073/pnas.0611500104 0611500104 [pii].

Earnest, A., Morgan, G., Mengersen, K., Ryan, L., Summerhayes, R., Beard, J., 2007.

Evaluating the effect of neighbourhood weight matrices on smoothing properties of Conditional Autoregressive (CAR) models. Int. J. Health Geogr. 6, 54. doi:http://dx.doi.org/10.1186/1476-072X-6-54.

Elliott, P., Wartenberg, D., 2004. Spatial epidemiology: current approaches and future challenges. Environ. Health Perspect. 112 (9), $998-1006$. doi:http://dx. doi.org/10.1289/ehp.6735. 
Engeland, A., Bjorge, T., Selmer, R.M., Tverdal, A., 2003. Height and body mass index in relation to total mortality. Epidemiology 14, $293-299$.

Feltbower, R.G., Manda, S.O.M., 2012. Bayesian bivariate disease mapping. In: Tu, Y.- K., Greenwood, C.D. (Eds.), Modern Methods for Epidemiology. Springer, Netherlands, Dordrecht, pp. 141-155. doi:http://dx.doi.org/10.1007/978-94- 007-3024-3_8.

Fuchs, V.R., 2004. Reflections on the socio-economic correlates of health. J. Health Econ. 23, 653-661. doi:http://dx.doi.org/10.1016/j.jhealeco.2004.04.004.

Gómez-Rubio, V., López-Quílez, A., 2010. Statistical methods for the geographical analysis of rare diseases. In: Posada de la Paz, M., Groft, S.C. (Eds.), Rare Diseases Epidemiology, Advances in Experimental Medicine and Biology. Springer, Netherlands, Dordrecht, pp. 151-171. doi:http://dx.doi.org/10.1007/978-90- 481-9485-8.

Galobardes, B., Shaw, M., Lawlor, D.A., Lynch, J.W., Davey Smith, G., 2006. Indicators of socioeconomic position (part 1). J. Epidemiol. Community Health 60, 7-12. doi:http://dx.doi.org/10.1136/jech.2004.023531.

Gao, W., Smyth, R., 2010. Health human capital, height and wages in China. J. Dev. Stud. 46, 466-484. doi:http://dx.doi.org/10.1080/00220380903318863.

Gautschi, T., Hangartner, D., 2006. Size Does Matter. Körpergrösse, Humankapital und Einkommen. Soz. Welt-Zeitschrift für sozialwissenschaftliche Forsch. und Prax, 10.7892/boris.19454.

Grasgruber, P., Sebera, M., Hrazdíra, E., Cacek, J., Kalina, T., 2016. Major correlates of male height: a study of 105 countries. Econ. Hum. Biol. 21, 172-195. doi:http:// dx.doi.org/10.1016/j.ehb.2016.01.005.

Hübler, O., 2009. The nonlinear link between height and wages in Germany, 1985- 2004. Econ. Hum. Biol. 7, 191-199. doi:http://dx.doi.org/10.1016/j. ehb.2009.06.003.

Hallström, L., Vereecken, C.a., Ruiz, J.R., Patterson, E., Gilbert, C.C., Catasta, G., Díaz, L.-E., Gómez-Martínez, S., González Gross, M., Gottrand, F., Hegyi, A., Lehoux, C., Mouratidou, T., Widham, K., Aström, A., Moreno, L.a., Sjöström, M., 2011.

Breakfast habits and factors influencing food choices at breakfast in relation to socio-demographic and family factors among European adolescents. The HELENA Study. Appetite 56, 649-657. doi:http://dx.doi.org/10.1016/j. appet.2011.02.019.

Harrower, M., Brewer, C.A., 2003. ColorBrewer.org: an online tool for selecting colour schemes for maps. Cartogr. J. 40, $27-37$. doi:http://dx.doi.org/10.1179/000870403235002042.

Hatton, T., Bray, B., 2010. Long run trends in the heights of European men, 19th-20th centuries. Econ. Hum. Biol. 8, 405-413. doi:http://dx.doi.org/10.1016/j. ehb.2010.03.001 S1570-677X(10)00022-5 [pii].

Heineck, G., 2005. Up in the skies? The relationship between body height and earnings in Germany. Labour 19, 469-489.

Hermanussen, M., Alt, C., Staub, K., Aßmann, C., Groth, D., 2014. The impact of physical connectedness on body height in Swiss conscripts. Anthropol. Anz. 71, 313-327. doi:http://dx.doi.org/10.1127/0003-5548/2014/0466.

Herpin, N., 2005. Love, careers, and heights in France, 2001. Econ. Hum. Biol. 420- 449.

Hiermeyer, M., 2009. Height and BMI values of German conscripts in 2000, 2001 and 1906. Econ. Hum. Biol. 7, 366-375. doi:http://dx.doi.org/10.1016/j. ehb.2009.07.005.

Hodges, J.S., Reich, B.J., 2010. Adding spatially-correlated errors can mess up the fixed effect you love. Am. Stat. 54 (4), 325-333. doi:http://dx.doi.org/10.1198/ tast.2010.10052.

Huang, Y., van Poppel, F., Lumey, L.H., 2015. Differences in height by education among 371,105 Dutch military conscripts. Econ. Hum. Biol. 17, 202207. doi: http://dx.doi.org/10.1016/j.ehb.2014.11.002.

International Labour Organization, 2014. International Standard Classification of Occupations (ISCO) [WWW Document]. . URL http://www.ilo.org/public/ english/bureau/stat/isco/.

Komlos, J., 2008. Anthropometric history. In: Durlauf, S.N., Blume, L.E. (Eds.), The New Palgrave Dictionary of Economics. Palgrave Macmillan, Basingstoke, London.

Kues, A.B., 2010. Taller - healthier - more equal? The biological standard of living in Switzerland in the second half of the 20th century. Econ. Hum. Biol. 8, 67-79. doi:http://dx.doi.org/10.1016/j.ehb.2009.09.002.

Logistikbasis der Armee LBA San, 2014. Militärärztlicher Dienst [WWW Document].

. URL http://www.lba.admin.ch/internet/lba/de/home/themen/sanit/milit. html.

Magnusson, P.K.E., Rasmussen, F., Gyllensten, U.B., 2006. Height at age 18 years is a strong predictor of attained education later in life: cohort study of over 950,000 Swedish men. Int. J. Epidemiol. 35, 658-663. doi:http://dx.doi.org/10.1093/ije/ dyl011 dyl011 [pii].

Mayer, K., 1951. Cultural pluralism and linguistic equilibrium in Switzerland. Am. Sociol. Rev. 16, 157-163.

McEvoy, B.P., Visscher, P.M., 2009. Genetics of human height. Econ. Hum. Biol. 7, 294-306. doi:http://dx.doi.org/10.1016/j.ehb.2009.09.005. 
Moser, A., Panczak, R., Zwahlen, M., Clough-Gorr, K.M., Spoerri, A., Stuck, A.E., Egger, M., 2014. What does your neighbourhood say about you? A study of life expectancy in 1.3 million Swiss neighbourhoods. J. Epidemiol. Community Health 68, 1-8. doi:http://dx.doi.org/10.1136/jech-2014204352.

Natale, V., Rajagopalan, A., 2014. Worldwide variation in human growth and the World Health Organization growth standards: a systematic review. BMJ Open 4, e003735. doi:http://dx.doi.org/10.1136/bmjopen-2013-003735.

Novembre, J., Johnson, T., Bryc, K., Kutalik, Z., Boyko, A.R., Auton, A., Indap, A., King, K. S., Bergmann, S., Nelson, M.R., Stephens, M., Bustamante, C.D., 2008. Genes mirror geography within Europe. Nature 456, 98-101. doi:http://dx.doi.org/ 10.1038/nature07331.

Panczak, R., Galobardes, B., Voorpostel, M., Spoerri, A., Zwahlen, M., Egger, M., 2012. A Swiss neighbourhood index of socioeconomic position: development and association with mortality. J. Epidemiol. Community Health 66, 1129-1136. doi: http://dx.doi.org/10.1136/jech-2011-200699.

Panczak, R., Zwahlen, M., Woitek, U., Rühli, F.J., Staub, K., Ruhli, F.J., Woitek, U., Pfister, C., Rühli, F.J., Henneberg, M., Panczak, R., Zwahlen, M., Woitek, U., Rühli, F.J., Staub, K., 2014. Socioeconomic, temporal and regional variation in body mass index among 188,537 Swiss male conscripts born between 1986 and 1992. PLoS One 9, e96721. doi:http://dx.doi.org/10.1371/journal.pone.0096721.

Panczak, R., Held, L., Moser, A., Jones, P., Ruhli, F., Staub, K., 2016. Finding big shots: small-area mapping and spatial modelling of obesity among Swiss male conscripts. BMC Obes. 3, 1-12.

Persico, N., Postlewaite, A., Silverman, D., 2004. The effect of adolescent experience on labor market outcomes: the case of height. J. Polit. Econ. 112, 1019-1053. doi: http://dx.doi.org/10.1086/422566.

Rühli, F., Henneberg, M., Woitek, U., 2008. Variability of height, weight, and body mass index in a Swiss armed forces 2005 census. Am. J. Phys. Anthropol. 137, 457-468. doi:http://dx.doi.org/10.1002/ajpa.20889.

Richardson, S., Thomson, A., Best, N., Elliott, P., 2004. Interpreting posterior relative risk estimates in disease-mapping studies. Environ. Health Perspect. 112 (9), 1016-1025. doi:http://dx.doi.org/10.1289/ehp.6740.

Rue, H., Martino, S., Chopin, N., 2009. Approximate Bayesian inference for latent Gaussian models by using integrated nested Laplace approximations. J. R. Stat. Soc. Ser. B: (Stat. Methodol. 71, 319-392. doi:http://dx.doi.org/10.1111/j.1467- 9868.2008.00700.x.

Schrödle, B., Held, L., 2010. A primer on disease mapping and ecological regression using INLA. Comput. Stat. 26, 241-258. doi:http://dx.doi.org/10.1007/s00180- 010-0208-2.

Schultz, T.P., 2002. Wage gains associated with height as a form of health human capital. Am. Econ. Rev. 92, 349-353. doi:http://dx.doi.org/10.1257/ 000282802320191598.

Spiegelhalter, D.J., Best, N.G., Carlin, B.P., van der Linde, A., 2002. Bayesian measures of model complexity and fit. J. R. Stat. Soc. Ser. B: (Stat. Methodol.) 64, 583-639. doi:http://dx.doi.org/10.1111/1467-9868.00353.

Spiegelhalter, D.J., Abrams, K.R., Myles, J.P., 2004. Bayesian Approaches to Clinical Trials and Health-Care Evaluation. John Wiley \& Sons.

Staub, K., Rühli, F.J., Woitek, U., Pfister, C., 2010. BMI distribution/social stratification in Swiss conscripts from 1875 to present. Eur. J. Clin. Nutr. 64, 335-340.

Staub, K., Rühli, F., Woitek, U., Pfister, C., 2011. The average height of 18- and 19-year- old conscripts $(\mathrm{N}=458,322)$ in Switzerland from 1992 to 2009, and the secular height trend since 1878. Swiss Med. Wkly. 141, w13238. doi:http://dx.doi.org/ 10.4414/smw.2011.13238.

Staub, K., Woitek, U., Pfister, C., Rühli, F., 2013a. Overview over 10 years of anthropometric history in Switzerland: the secular trend, regional and socioeconomic differences in body height and shape since the 19th century. Bull. Schweiz. Ges. Anthropol. 18, 37-50.

Staub, K., Woitek, U., Rühli, F., 2013b. Impact and Pitfalls of Conscription Data. In: Hermanussen, M. (Ed.), Auxology, Schweizerbart, pp. 146-149.

Staub, K., Floris, J., Woitek, U., Rühli, F., 2014. From left-skewness to symmetry: how body-height distribution among Swiss conscripts has changed shape since the late 19th century. Ann. Hum. Biol. 4460, 1-8. doi:http://dx.doi.org/10.3109/ 03014460.2014.942366.

Steckel, R.H., 2009. Heights and human welfare: recent developments and new directions. Explor. Econ. Hist. 46, 1-23. doi:http://dx.doi.org/10.1016/j. eeh.2008.12.001.

Stulp, G., Barrett, L., 2016. Evolutionary perspectives on human height variation.

Biol. Rev. 91, 206-234. doi:http://dx.doi.org/10.1111/brv.12165.

Swiss Federal Statistical Office, 2014a. Nomenklaturen Räumliche Gliederungen [WWW Document] . URL

https://www.bfs.admin.ch/bfs/de/home/statistiken/ querschnittsthemen/raeumliche-analysen/raeumliche-gliederungen.html.

Swiss Federal Statistical Office, 2014b. Distribution des statuts migratoires dans la population de nationalité suisse résidante permanente âgée de 15 ans ou plus. Swiss Federal Statistical Office, Bern.

The Emerging Risk Factors Collaboration, 2012. Adult height and the risk of cause- specific death and vascular morbidity in 1 million people: individual participant meta-analysis. Int. J. Epidemiol. 41, 1419-1433. doi:http://dx.doi.org/10.1093/ije/dys086.

The R Core Team, 2014. R: A Language and Environment for Statistical Computing. R Foundation for Statistical Computing, Vienna, Austria. 
Vogl, T.S., 2014. Height, skills, and labor market outcomes in Mexico. J. Dev. Econ. 107, 84-96. doi:http://dx.doi.org/10.1016/j.jdeveco.2013.11.007. 
Table 1. Distribution of study population and mean height across covariates. 175,916 male Swiss conscripts. SD standard deviation, Swiss-SEP - see (Panczak et al., 2012).

\begin{tabular}{|c|c|c|c|c|c|}
\hline Variable & Category & $\mathbf{N}$ & $\%$ & Mean & SD \\
\hline \multirow[t]{4}{*}{ Profession } & Pupil & 170386 & $10 \%$ & 178.63 & 6.58 \\
\hline & Low & 730101 & $42 \%$ & 177.83 & 6.45 \\
\hline & Medium & 430625 & $25 \%$ & 178.24 & 6.45 \\
\hline & High & 410804 & $24 \%$ & 178.59 & 6.47 \\
\hline \multirow[t]{5}{*}{ Swiss-SEP index } & 1st (lowest) & 180730 & $11 \%$ & 177.74 & 6.40 \\
\hline & $2 n d$ & 400938 & $23 \%$ & 177.86 & 6.42 \\
\hline & 3rd quintile & 510104 & $29 \%$ & 178.13 & 6.49 \\
\hline & 4th & 430313 & $25 \%$ & 178.44 & 6.50 \\
\hline & 5th (highest) & 210831 & $12 \%$ & 178.84 & 6.47 \\
\hline \multirow[t]{3}{*}{ Language region } & German & 1340245 & $76 \%$ & 178.36 & 6.47 \\
\hline & French & 340519 & $20 \%$ & 177.78 & 6.49 \\
\hline & Italian & 70152 & $4 \%$ & 177.08 & 6.39 \\
\hline All & & 1750916 & $100 \%$ & 178.19 & 6.48 \\
\hline
\end{tabular}


Table 2. Comparison of fitted models. DIC - deviance information criterion (see (Spiegelhalter et al., 2002)), Swiss-SEP - see (Panczak et al., 2012). Lower values of DIC indicate better model fit.

\begin{tabular}{llll}
\hline Model & Random effects & Adjustment variables & DIC \\
\hline 1 & None & Professional status, Swiss-SEP & 101550873.4 \\
2 & & Professional status, Swiss-SEP, language region & 101550416.7 \\
3 & Spatially unstructured & None & 101560514.7 \\
4 & & Professional status, Swiss-SEP & 101550724.5 \\
5 & Professional status, Swiss-SEP, language region & 101550237.8 \\
6 & Npatially unstructured and spatially structured & None & 101550513.2 \\
7 & & Professional status, Swiss-SEP & 101540946.0 \\
8 & & Professional status, Swiss-SEP, language region & 101550047.3 \\
\hline
\end{tabular}


Table 3. Differences and constant estimates of height (in $\mathrm{cm}$ ) and their $95 \%$ credible intervals from models with spatially unstructured and spatially structured random effects, unadjusted (Model 6), adjusted for professional status and Swiss-SEP (Model 7) and additionally adjusted for language region (Model 8). Swiss-SEP - see (Panczak et al., 2012).

\begin{tabular}{|c|c|c|c|c|}
\hline Variable & Category & Model 6 & Model 7 & Model 8 \\
\hline \multirow[t]{4}{*}{ Professional status } & Pupil & - & $0.16(0.05-0.28)$ & $0.17(0.05-0.28)$ \\
\hline & Low & - & $-0.34(-0.42$ to -0.27$)$ & $-0.35(-0.42$ to -0.27$)$ \\
\hline & Medium & - & 0.00 (ref.) & 0.00 (ref.) \\
\hline & High & - & $0.63(0.53-0.72)$ & $0.65(0.56-0.74)$ \\
\hline $\begin{array}{l}\text { Swiss-SEP (per } 10 \text { unit } \\
\text { increase) }\end{array}$ & - & & $0.27(0.20-0.33)$ & $0.28(0.23-0.34)$ \\
\hline \multirow[t]{3}{*}{ Language region } & German & - & - & 0.00 (ref.) \\
\hline & French & - & - & $-0.66(-0.83$ to -0.49$)$ \\
\hline & Italian & - & - & $-1.54(-1.88$ to -1.20$)$ \\
\hline Constant & & 178.05 (178.01-178.09) & 176.38 (175.96-176.79) & 176.55 (176.21-176.89) \\
\hline Residual variance & & 39.7 & 39.7 & 39.7 \\
\hline \multirow[t]{2}{*}{ Variance of random effects } & Total & 0.431 & 0.382 & 0.064 \\
\hline & $\begin{array}{l}\text { Spatial } \\
\text { component }\end{array}$ & 0.412 & 0.371 & 0.045 \\
\hline
\end{tabular}


Figure 1. Postcode level estimates of height differences (model $6=$ unadjusted; model $7=$ adjusted for professional status, Swiss-SEP; model $8=$ model 2 , additionally adjusted for language region; all models with spatially unstructured and structured effects).

Estimates of height difference: 175,916 Swiss conscripts 18.5-20.5 year old, 2005-11.

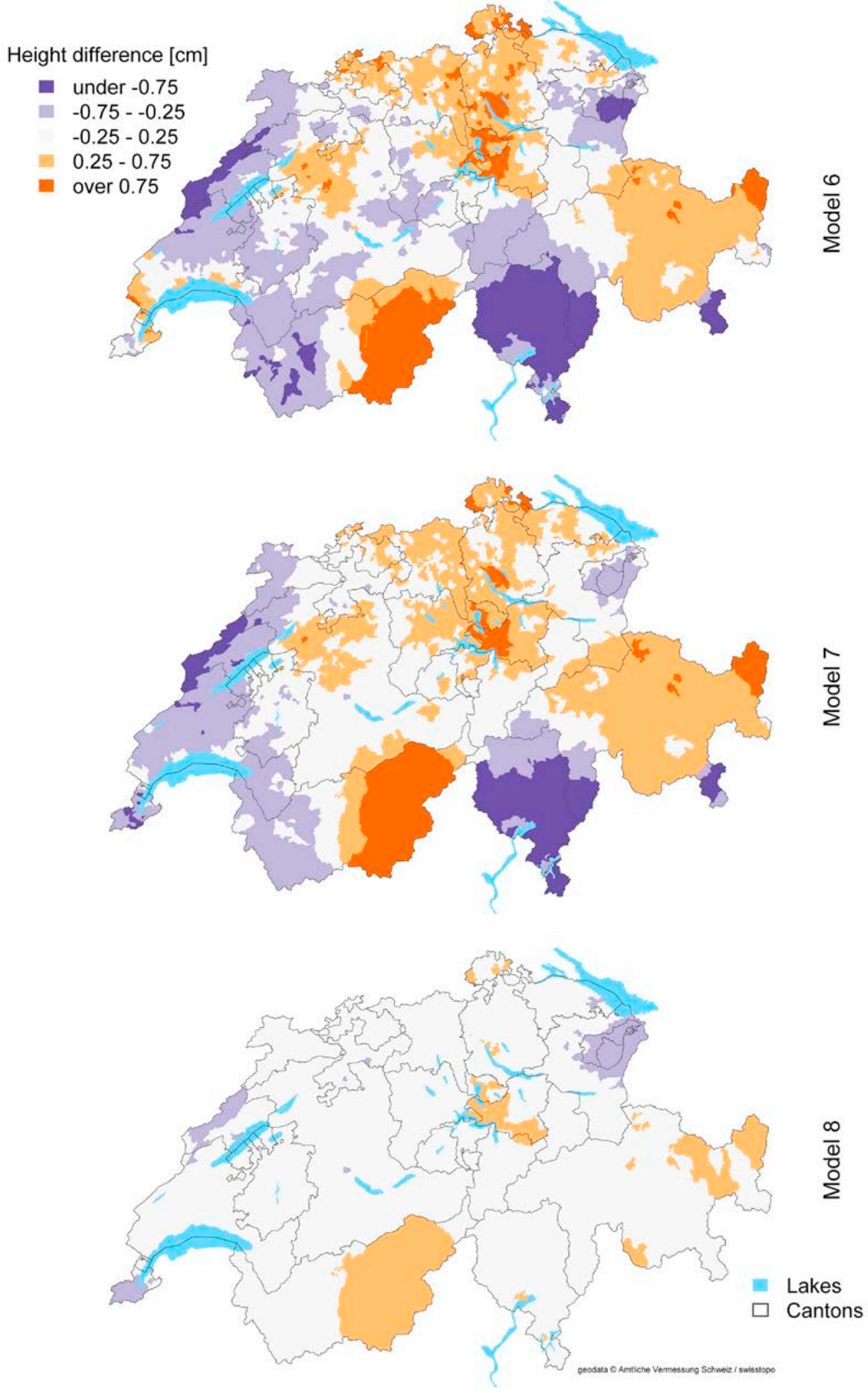


Figure 2. Postcode level estimates of posterior probabilities of height differences (model $6=$ unadjusted; model 7 = adjusted for professional status, Swiss-SEP; model $8=$ model 2 , additionally adjusted for language region; all models with spatially unstructured and structured effects).

Estimates of posterior probability of height difference.

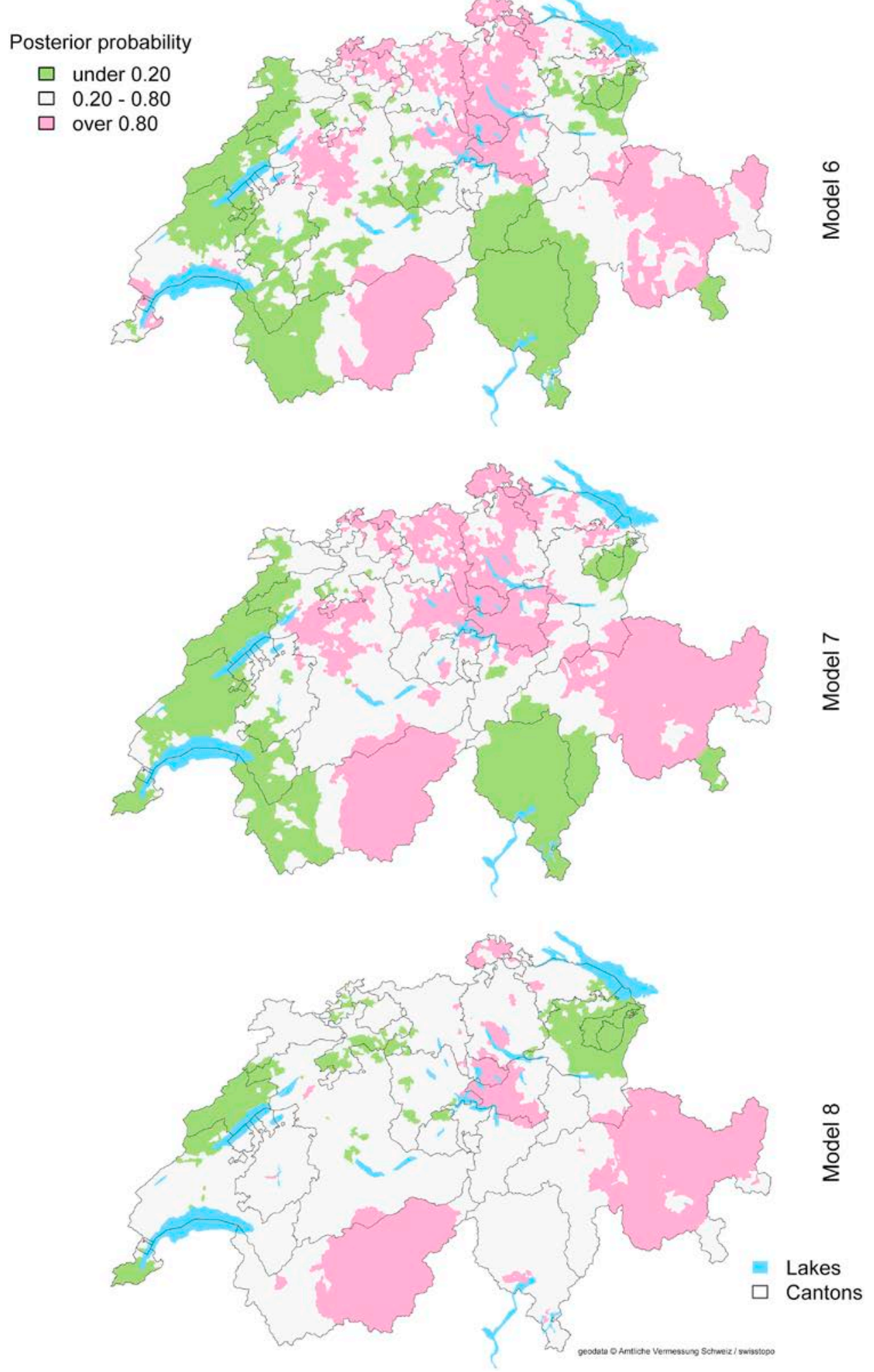




\section{Competing interests}

None declared.

\section{Authors' contributions}

Conceived and designed the experiments: RP LH AM FR KS. Analysed the data: RP LH AM. Wrote first draft: KS RP. Wrote the paper: all authors. Obtained funding: KS FR. Obtained data: KS FR.

\section{Acknowledgments}

Swiss Federal Office of Public Health and Mäxi Foundation (for funding); Andreas Stettbacher, Chief Medical Surgeon of the Swiss Armed Forces (for providing the individual conscription data); Franz Frey, Tiziano Angelelli, Matthias Egger, Dominik Schori, Karen Hofmann, Thomas Abel, Marcel Zwahlen, Michael Herma- nussen, Marek Brabec, John Komlos, Ulrich Woitek, Joël Floris, Nikola Koepke, Marta Blangiardo, Garyfallos Konstantinoudis, Inas Kelly, Abigail Bouwman and Jörg Baten (for helpful comments). 


\section{Supplementary data}

Supplementary Figure S1: Swiss Cantons.

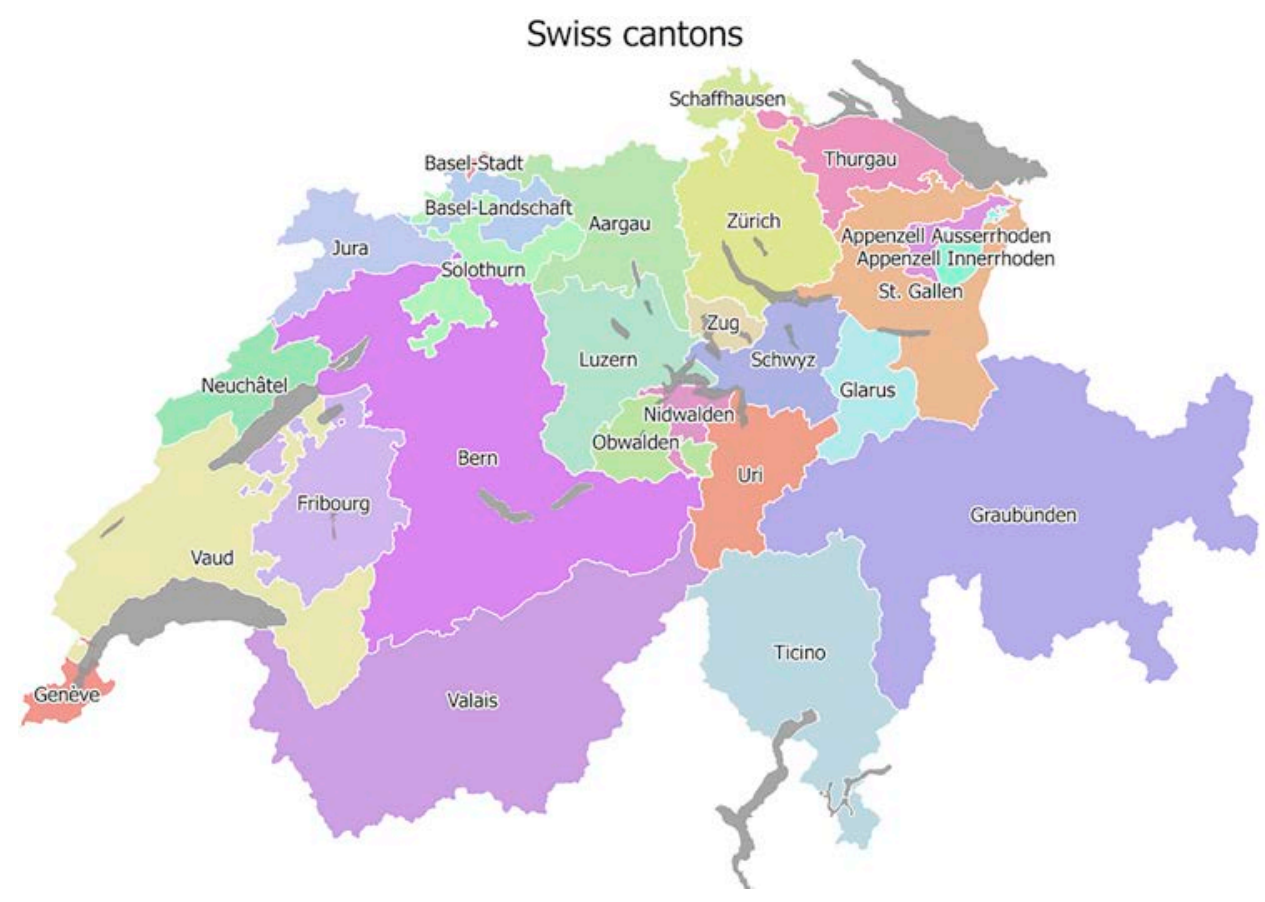


Supplementary Figure S2: Language region and Swiss-SEP of postcodes.

\section{Ecological data - Swiss postcodes}

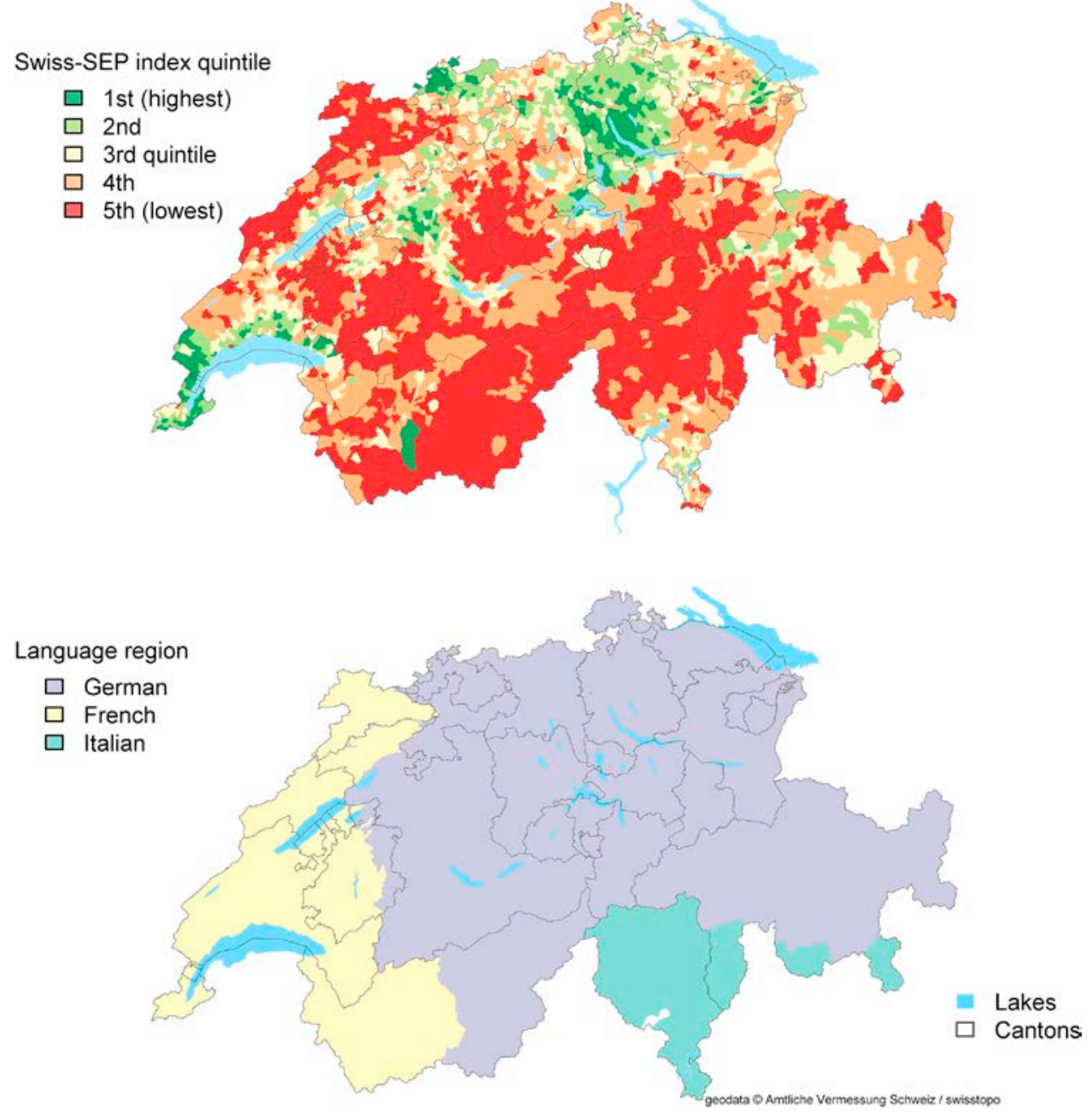


Supplementary Table S1: Coefficients and their 95\% credible intervals from models without random effects, adjusted for professional status and Swiss-SEP (Model 1) and additionally adjusted for language region (Model 2). DIC - deviance information criterion (see (Spiegelhalter et al., 2002)), Swiss-SEP - see (Panczak et al., 2012). Lower values of DIC indicate better model fit.

\begin{tabular}{|l|l|r|r|}
\hline Variable & Category & \multicolumn{1}{l|}{ Model 1 } & \multicolumn{1}{l|}{ Model 2 } \\
\hline Professional status & Pupil & $0.26(0.15$ to 0.37$)$ & 0.16 (0.05 to 0.28) \\
\hline & Low & $-0.35(-0.43$ to -0.28$)$ & -0.36 (-0.43 to -0.28$)$ \\
\hline & Medium & 0.00 (ref.) & 0.00 (ref.) \\
\hline & High & $0.34(0.25$ to 0.42$)$ & 0.65 (0.56 to 0.74) \\
\hline Swiss-SEP (per 10 unit increase) & & $0.38(0.34$ to 0.42$)$ & 0.27 (0.23 to 0.31) \\
\hline Language region & German & - & 0.00 (ref.) \\
\hline & French & -0.74 (-0.82 to -0.66$)$ \\
\hline Constant & Italian & -1.43 (-1.59 to -1.28$)$ \\
\hline Residual variance & & $175.80(175.53$ to 176.06$)$ & 176.66 (176.39 to 176.94$)$ \\
\hline
\end{tabular}


Supplementary Table S2: Coefficients and their 95\% credible intervals from models with spatially unstructured random effects, unadjusted (Model 3), adjusted for professional status and Swiss-SEP (Model 4 ) and additionally adjusted for language region (Model 5). Lower values of DIC indicate better model fit. DIC - deviance information criterion (see (Spiegelhalter et al., 2002), Swiss-SEP - see (Panczak et al., 2012).

\begin{tabular}{|c|c|c|c|c|}
\hline Variable & Category & Model 3 & Model 4 & Model 5 \\
\hline \multirow[t]{4}{*}{ Professional status } & Pupil & - & $0.25(0.14$ to 0.37$)$ & $0.17(0.05$ to 0.28$)$ \\
\hline & Low & - & $-0.34(-0.42$ to -0.27$)$ & $-0.35(-0.43$ to -0.27$)$ \\
\hline & Medium & - & 0.00 (ref.) & 0.00 (ref.) \\
\hline & High & - & $0.36(0.27$ to 0.44$)$ & 0.65 (0.56 to 0.74$)$ \\
\hline Swiss-SEP (per 10 unit increase) & & - & $0.39(0.34$ to 0.43$)$ & $0.28(0.23$ to 0.32$)$ \\
\hline \multirow[t]{3}{*}{ Language region } & German & - & - & 0.00 (ref.) \\
\hline & French & - & - & $-0.73(-0.81$ to -0.64$)$ \\
\hline & Italian & - & - & $-1.43(-1.59$ to -1.27$)$ \\
\hline Constant & & 178.18 (178.15 to 178.22$)$ & 175.75 (175.47 to 176.02$)$ & 176.59 (176.30 to 176.87$)$ \\
\hline \multicolumn{2}{|l|}{ Residual variance } & 39.7 & 39.7 & 39.7 \\
\hline Variance of random effects & Total & 0.019 & 0.019 & 0.021 \\
\hline
\end{tabular}


Published in final edited form as: Econ Hum Biol. 2017 Aug;26:61-69. doi: 10.1016/j.ehb.2017.01.005

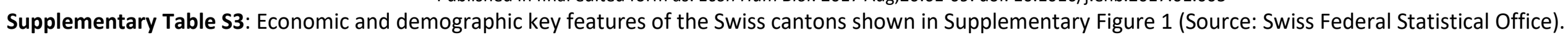

\begin{tabular}{|c|c|c|c|c|c|c|c|c|c|c|c|c|c|c|c|c|c|c|c|c|c|c|c|c|c|c|c|c|}
\hline & & & Swiss & tons (ir & he offic & order) & & & & & & & & & & & & & & & & & & & & & & \\
\hline & $\begin{array}{l}\text { Years } \\
\end{array}$ & $\begin{array}{l}\text { Switzer } \\
\text { land }\end{array}$ & $\mathrm{ZH}$ & $\overline{B E}$ & LU & UR & SZ & ow & NW & GL & $\overline{Z G}$ & FR & so & BS & BL & $\overline{S H}$ & AR & $\mathrm{Al}$ & SG & $\begin{array}{ll}\text { GR } \\
\text {. }\end{array}$ & AG & $\overline{T G}$ & $\mathrm{TI}$ & VD & VS & $\mathrm{NE}$ & GE & JU \\
\hline Population & & & & & & & & & & & & & & & & & & & & & & & & & & & & \\
\hline Inhabitants in 1000 & 2014 & 8237.7 & $\begin{array}{l}1446 \\
.4\end{array}$ & $\begin{array}{l}1009 \\
.4\end{array}$ & $\begin{array}{l}394 . \\
6\end{array}$ & 36.0 & $\begin{array}{l}152 . \\
8\end{array}$ & 36.8 & 42.1 & 39.8 & 120.1 & $\begin{array}{l}303 . \\
4\end{array}$ & $\begin{array}{l}263 . \\
7\end{array}$ & 190.6 & $\begin{array}{l}281 . \\
3\end{array}$ & 79.4 & 54.1 & 15.9 & $\begin{array}{l}495 . \\
8\end{array}$ & $\begin{array}{l}195 . \\
9\end{array}$ & $\begin{array}{l}645 . \\
3\end{array}$ & $\begin{array}{l}263 . \\
7\end{array}$ & $\begin{array}{l}350 . \\
4\end{array}$ & $\begin{array}{l}761 . \\
4\end{array}$ & $\begin{array}{l}331 . \\
8\end{array}$ & $\begin{array}{l}177 . \\
3\end{array}$ & 477.4 & 72.4 \\
\hline Change in $\%$ & $\begin{array}{l}2010- \\
2014\end{array}$ & 4.7 & 5.3 & 3.0 & 4.5 & 1.7 & 4.1 & 3.5 & 2.6 & 3.1 & 6.2 & 8.9 & 3.3 & 3.0 & 2.5 & 4.0 & 2.0 & 1.1 & 3.5 & 1.7 & 5.5 & 6.2 & 5.0 & 6.8 & 6.1 & 3.0 & 4.3 & 3.4 \\
\hline Age distribution in \% & 2014 & & & & & & & & & & & & & & & & & & & & & & & & & & & \\
\hline $0-19$ & & 20.2 & 19.6 & 19.1 & 20.8 & 20.6 & 20.3 & 20.9 & 18.7 & 19.4 & 20.3 & 23.1 & 19.3 & 16.6 & 19.3 & 18.9 & 20.5 & 22.5 & 20.9 & 18.5 & 20.4 & 20.7 & 18.5 & 22.2 & 20.2 & 21.6 & 21.1 & 21.9 \\
\hline $20-64$ & & 62.0 & 63.6 & 60.9 & 62.4 & 60.2 & 63.3 & 62.0 & 62.8 & 61.7 & 63.5 & 62.2 & 61.9 & 63.0 & 59.7 & 60.8 & 60.9 & 59.5 & 61.9 & 61.9 & 62.9 & 62.8 & 59.9 & 61.6 & 61.3 & 60.0 & 62.4 & 58.4 \\
\hline$>=65$ & & 17.8 & 16.8 & 19.9 & 16.8 & 19.2 & 16.4 & 17.1 & 18.6 & 18.8 & 16.2 & 14.8 & 18.8 & 20.4 & 21.0 & 20.2 & 18.6 & 18.1 & 17.2 & 19.6 & 16.6 & 16.4 & 21.6 & 16.2 & 18.5 & 18.4 & 16.5 & 19.6 \\
\hline $\begin{array}{l}\text { Proportion of foreigners in } \\
\%\end{array}$ & 2014 & 24.3 & 25.8 & 15.0 & 17.6 & 11.5 & 19.9 & 14.2 & 13.6 & 22.6 & 26.3 & 21.4 & 20.8 & 34.8 & 21.3 & 25.0 & 15.4 & 10.6 & 23.3 & 18.1 & 23.9 & 23.8 & 27.6 & 33.1 & 22.7 & 25.2 & 40.9 & 14.0 \\
\hline Main language in \% & 2013 & & & & & & & & & & & & & & & & & & & & & & & & & & & \\
\hline German & & 64.5 & 83.5 & 85.1 & 89.8 & 93.0 & 90.2 & 92.5 & 92.7 & 87.8 & 83.9 & 28.7 & 89.6 & 79.3 & 88.0 & 87.6 & 92.2 & 93.2 & 89.3 & 75.1 & 88.1 & 89.9 & 10.6 & 6.5 & 26.2 & 5.5 & 5.0 & 7.0 \\
\hline French & & 22.6 & 3.2 & 10.4 & 1.6 & 0.9 & 1.9 & 1.1 & 2.4 & 0.5 & 3.2 & 68.7 & 2.4 & 4.9 & 3.3 & 1.6 & 1.5 & 1.6 & 1.3 & 1.5 & 2.0 & 1.2 & 5.1 & 83.8 & 67.3 & 87.6 & 80.8 & 91.4 \\
\hline Italian & & 8.3 & 5.7 & 3.1 & 2.8 & 2.3 & 3.1 & 1.6 & 3.2 & 5.9 & 4.2 & 2.3 & 5.0 & 5.7 & 5.1 & 4.1 & 2.2 & & 3.3 & 12.7 & 4.9 & 3.8 & 88.2 & 5.2 & 3.8 & 6.2 & 6.9 & 3.2 \\
\hline Rhaeto-Romanic & & 0.5 & 0.3 & 0.1 & 0.2 & & 0.4 & & & & 0.2 & & 0.2 & 0.2 & 0.1 & & & & 0.3 & 14.9 & 0.2 & 0.3 & 0.1 & 0.0 & & & 0.0 & \\
\hline Englisch & & 4.7 & 6.6 & 2.9 & 2.9 & 1.8 & 4.7 & 1.7 & 4.0 & 2.3 & 9.0 & 3.0 & 2.7 & 8.4 & 4.7 & 3.9 & 3.0 & & 2.7 & 2.5 & 3.7 & 2.5 & 3.1 & 7.5 & 2.6 & 3.3 & 10.6 & 1.3 \\
\hline Religion in \% & 2013 & & & & & & & & & & & & & & & & & & & & & & & & & & & \\
\hline & & & & & & & & & & & & & & & & & & & & & & & & & & & & \\
\hline
\end{tabular}


Published in final edited form as: Econ Hum Biol. 2017 Aug;26:61-69. doi: 10.1016/j.ehb.2017.01.005

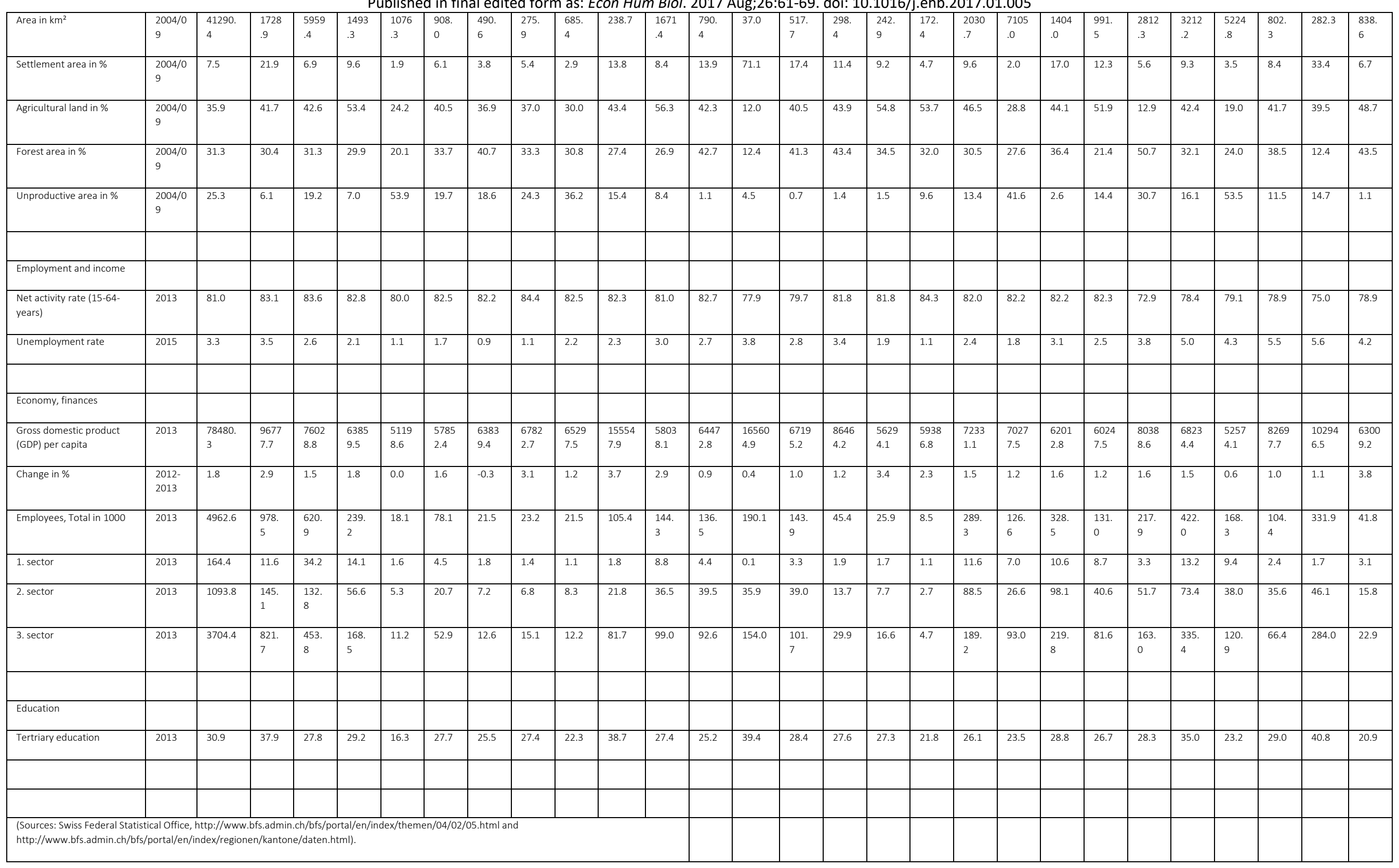

